\title{
Stress and Heart Rate Variability: A Meta-Analysis and Review of the Literature
}

\author{
Hye-Geum Kim ${ }^{1}$, Eun-Jin Cheon ${ }^{2}$, Dai-Seg Bai ${ }^{3}$, Young Hwan Lee ${ }^{2 \star} \bowtie$, and Bon-Hoon Koo ${ }^{1 \star 凶}$ \\ ${ }^{1}$ Department of Psychiatry, College of Medicine, Yeungnam University, Daegu, Republic of Korea \\ ${ }^{2}$ Department of Pediatrics, College of Medicine, Yeungnam University, Daegu, Republic of Korea \\ ${ }^{3}$ Division of Clinical Psychology, Department of Psychiatry, Yeungnam University Medical Center, Daegu, Republic of Korea
}

\begin{abstract}
Objective Physical or mental imbalance caused by harmful stimuli can induce stress to maintain homeostasis. During chronic stress, the sympathetic nervous system is hyperactivated, causing physical, psychological, and behavioral abnormalities. At present, there is no accepted standard for stress evaluation. This review aimed to survey studies providing a rationale for selecting heart rate variability (HRV) as a psychological stress indicator.

Methods Term searches in the Web of Science ${ }^{\circledR}$, National Library of Medicine (PubMed), and Google Scholar databases yielded 37 publications meeting our criteria. The inclusion criteria were involvement of human participants, HRV as an objective psychological stress measure, and measured HRV reactivity.

Results In most studies, HRV variables changed in response to stress induced by various methods. The most frequently reported factor associated with variation in HRV variables was low parasympathetic activity, which is characterized by a decrease in the high-frequency band and an increase in the low-frequency band. Neuroimaging studies suggested that HRV may be linked to cortical regions (e.g., the ventromedial prefrontal cortex) that are involved in stressful situation appraisal.

Conclusion In conclusion, the current neurobiological evidence suggests that HRV is impacted by stress and supports its use for the objective assessment of psychological health and stress.

Psychiatry Investig 2018;15(3):235-245
\end{abstract}

Key Words Heart rate variability, Stress, Autonomic nervous system.

\section{INTRODUCTION}

Hans Selye defined stress as "a response to change in order to maintain the state of stability or homology that the body has maintained against the stimulus to break the mental and physical balance and stability of the body." ${ }^{\prime \prime}$ Stress was also defined by Kenneth Hambly as a maladaptive state in which the sympathetic nervous system is overactivated, causing acute

\footnotetext{
Received: May 5, 2017 Revised: August 1, 2017

Accepted: August 17, 2017

$\triangle$ Correspondence: Bon-Hoon Koo, MD, PhD

Department of Psychiatry, College of Medicine, Yeungnam University, $170 \mathrm{Hy}$ eonchung-ro, Nam-gu, Daegu 42415, Republic of Korea

Tel: +82-53-620-3343, Fax: +82-53-629-0256, E-mail: vijnana@chol.com

$\triangle$ Correspondence: Young Hwan Lee, MD, PhD

Department of Pediatrics, College of Medicine, Yeungnam University, $170 \mathrm{Hy}-$ eonchung-ro, Nam-gu, Daegu 42415, Republic of Korea

Tel: +82-53-640-6999, Fax: +82-53-629-2252, E-mail: yhlee3535@ynu.ac.kr

*These authors contributed equally to this work.

(c) This is an Open Access article distributed under the terms of the Creative Commons Attribution Non-Commercial License (http://creativecommons.org/licenses/by$\mathrm{nc} / 4.0$ ) which permits unrestricted non-commercial use, distribution, and reproduction in any medium, provided the original work is properly cited.
}

or chronic physical, psychological, and behavioral impairment. ${ }^{2}$ The search for stress biomarkers remains a challenging task for researchers and clinicians as there are several obstacles. One obstacle is a lack of consensus on the definition of stress. Moreover, we lack a comprehensive framework for investigating how organisms function in and adapt to constantly changing environments. ${ }^{3}$ At present, there is no universally recognized standard for stress evaluation. A number of studies using existing stress measurement methods (e.g., psychological measures of stress) and examining biological markers (e.g., cortisol, amylase) have been performed. Moreover, studies on heart rate variability (HRV) and stress are increasing in frequency. HRV is the fluctuation of the length of heart beat intervals. ${ }^{4} \mathrm{HRV}$ represents the ability of the heart to respond to a variety of physiological and environmental stimuli. ${ }^{5}$ Low HRV conveys a monotonously regular heart rate. Moreover, low HRV is associated with impaired regulatory and homeostatic autonomic nervous system (ANS) functions, which reduce the body's ability to cope with internal and external stressors. Thus, HRV is a noninvasive electrocardiographic method that can 
be used to measure the ANS in a variety of clinical situations (e.g., during psychological stress evaluations). ${ }^{6}$ Many researchers have conducted studies that used HRV to measure stress, operating under the assumption that HRV is a reliable index of stress. However, few studies have confirmed whether HRV is a good indicator of stress. In this review, we examined the literature providing a rationale for selecting HRV as a reliable indicator of psychological stress. The value of HRV as a stress indicator must be assessed to support its future clinical use as a noninvasive and simple diagnostic test.

\section{METHODS}

The Web of Science ${ }^{\circledR}$ (WoS), National Library of Medicine (PubMed), and Google Scholar databases were searched for articles published from 2007 to 2017 pertaining to psychosocial stress and HRV. The following combination of terms was used for each database search: 1) WOS, "[Title (TI)=(stress) AND TI=('Heart rate' OR 'Heart Rate Variability' OR 'HRV' OR ‘Cardiac Vagal Control’ OR ‘Cardiac Vagal Tone’ OR 'Au- tonomic Nervous System' OR 'Cardio-Vascular Reactivity')]”; 2) PubMed, "stress (Title) AND ['HRV' (Title/Abstract) OR 'Heart Rate Variability' (Title/Abstract)]"; and 3) Google Scholar, "allintitle: stress AND ('Heart Rate Variability' OR 'HRV')." The inclusion criteria were that each study involving human participants, used HRV as an objective measure of psychological stress, and measured HRV reactivity by evaluating any HRV variables calculated using frequency-based or time-based measures. Secondary references and other literature providing theoretical evidence for selecting HRV as a stress indicator or the role of the ANS in psychological stress and heart rate were also included in the study. Each of the database searches yielded 107 studies matching the inclusion criteria. Subsequently, we excluded studies that did not concur with the purpose of the literature review (e.g., studies assuming HRV is an objective measure of psychological stress and using it as a dependent variable). Ultimately, 37 studies meeting our criteria were selected for this review (Figure 1).

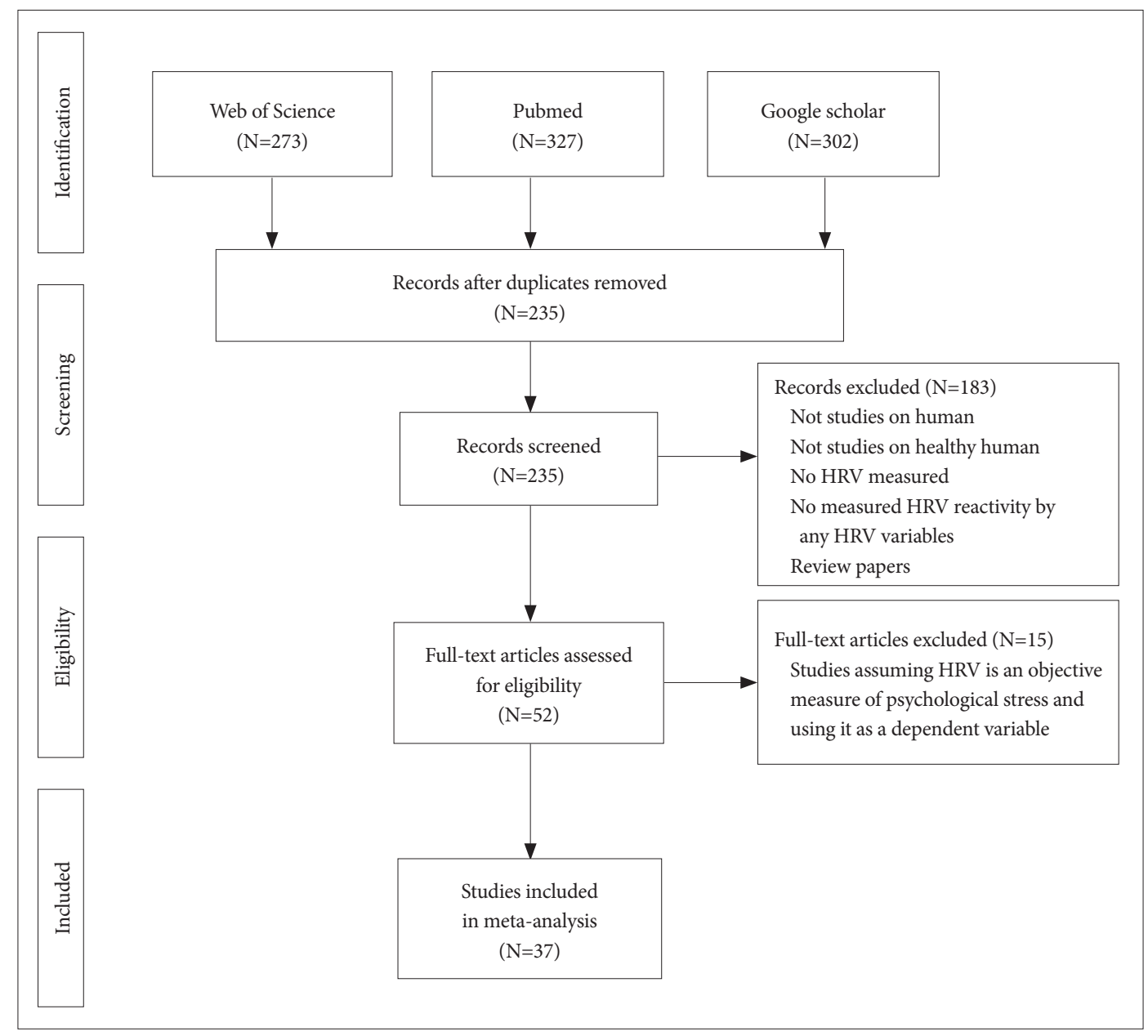

Figure 1. Flow chart of study selection in the meta-analysis. HRV: heart rate variability. 


\section{RESULTS}

\section{Autonomic regulation of psychological stress conditions}

The two main pathways by which psychological stress affects the body are the hypothalamic-pituitary-adrenal (HPA) axis and sympathetic nervous system (SNS). ${ }^{7}$ The ANS and HPA axis are highly coordinated and interconnected. ${ }^{8}$ The ANS quickly promotes physiological changes through the SNS and parasympathetic nervous system (PNS). The PNS promotes the sympathetic response to stress, commonly referred to as a fight or flight response, by withdrawing the inhibitory effect. ${ }^{9}$ A series of changes follows, including the release of noradrenaline from the locus coeruleus. ${ }^{10}$ During the stress response, the HPA axis triggers a series of endocrine changes, beginning with the release of corticotropin releasing hormone from the hypothalamus. ${ }^{8,11}$ Specifically, the PNS plays an important role in alleviating the stress response of individuals by inhibiting or inhibiting the SNS and HPA axis. ${ }^{8}$ Stress is associated with variations in autonomic activity that disrupt homeostatic processes. ${ }^{9}$ The ANS responds to the needs of the internal viscera as well as external stimuli. Homeostasis is associated with the regulation of internal viscera, whereas the stress response prioritizes external stimuli over internal needs. Thus, stress occurs when an organism's physiological demands are no longer adequately fulfilled by the PNS. Consequently, the measurement of parasympathetic tone may serve as an index of stress and stress vulnerability. Moreover, stasis, which is a lack of endogenous variability in neurally mediated peripheral systems (e.g., heart rate), is a sign of severe physiological distress. ${ }^{9}$

The homeostatic functions of the ANS are demonstrated by the baroreceptor-heart rate reflex, a reciprocal change in the activities of the ANS. ${ }^{12}$ Baroreceptor reflexes are organized largely within lower central autonomic substrates at the brainstem level. However, through the evolutionary development of the rostral brain systems, these lower autonomic systems became integrated with higher neural networks. ${ }^{13}$ The limbic system and forebrain including the hypothalamus, amygdala, and medial prefrontal cortex, have been shown to issue synaptic projections to brainstem reflex networks as well as to autonomic regions. ${ }^{12}$ Stressors can lead to an inhibition or shift in the set point of baroreceptor reflexes. ${ }^{12,14}$ Brainstem baroreceptor reflexes exert reciprocal control over the two autonomic branches (i.e., SNS and PNS). ${ }^{12}$

The reciprocal mode of autonomic control can vary under different circumstances. Using selective pharmacological blockades targeting the SNS and PNS, Berntson et al. ${ }^{13}$ found that orthostatic challenges and standard psychological stressors produced distinct patterns of control. Responses to ortho- static stress showed minimal individual variation. In contrast, psychological stressors produced widespread individual differences in the autonomic response. In response to psychological stressors, participants either showed sympathetic activation, vagal withdrawal, or a reciprocal pattern of autonomic response. ${ }^{13}$ These findings show that individuals differ in how they respond to psychological stressors.

\section{Autonomic cardiac control}

Although cardiac automaticity is intrinsic to various pacemaker tissues, heart rate (HR) and rhythm are largely under the control of the ANS. ${ }^{15} \mathrm{HR}$ is controlled by the balancing action of the SNS and PNS branches. The parasympathetic influence on $\mathrm{HR}$ is mediated by the release of acetylcholine from the vagus nerve. Muscarinic acetylcholine receptors respond to this release by increasing cell membrane $\mathrm{K}^{+}$conductance. ${ }^{16,17}$ The sympathetic influence on HR is mediated by the release of epinephrine and norepinephrine. $\beta$-adrenergic receptors are activated by the release of these hormones, which results in cAMP-mediated phosphorylation of membrane proteins. ${ }^{18}$ Increased SNS or diminished PNS activity results in cardioacceleration, whereas decreased SNS or increased PNS activity causes cardio-deceleration. ${ }^{5}$ The SNS mainly acts on the ventricular muscles and increases their contractility. Moreover, the SNS increases the excitation frequency, excitation conduction velocity, and excitability of the sinoatrial (SA) node. When the SNS is maximally stimulated, the magnitude of the HR and contractility can triple and double, respectively. The PNS primarily acts on the SA and atrioventricular (AV) nodes to reduce HR. Vagal and sympathetic activity constantly interacts. As the SA node is rich in acetylcholinesterase, the effect of the vagal impulse is brief, owing to rapid hydrolysis of acetylcholine. ${ }^{19,20}$ Under resting conditions, vagal tone prevails over sympathetic activity, and variations in the heart period are largely dependent on vagal modulation. When the SNS and PNS are removed, the HR rises above steady-state rates. Vagal dominance occurs when the vagus nerve, which is a parasympathetic nerve in the stable state, is more active than sympathetic nerves. Dysregulation of the autonomic nervous control of the cardiovascular system is associated with increased sympathetic and reduced parasympathetic tone and plays an important role in coronary artery disease and the genesis of potentially lethal ventricular arrhythmias. ${ }^{6,21}$ Separate rhythmic contributions from sympathetic and parasympathetic autonomic activity modulate the HR intervals of the QRS complex in the electrocardiogram (ECG) at distinct frequencies. In this context, the degree of variability in the HR provides information about the functioning of nervous control on the HR and the heart's ability to respond. Since the heart is not a metronome and its beats are irregular, HRV is 
normal and to be expected. Moreover, HRV indicates the heart's ability to respond to multiple physiological and environmental events, (e.g., breathing, physical exercise, mental stress, hemodynamic and metabolic changes, and sleep and orthostatism) and compensate for disease-induced disorders. ${ }^{5,22-25} \mathrm{HRV}$ can be used as a valuable tool to measure the sympathetic and parasympathetic function of the ANS. ${ }^{5}$

\section{Theoretical significance of heart rate variability}

Long before the modern technology of HRV was invented, physicians recognized the potential importance of heart rhythms. In 1847, Ludwig was able to observe a quickening of pulse rate with inhalation and a slowing with exhalation in the dog. ${ }^{26}$ This was the first report of respiratory sinus arrhythmia (RSA). Moreover, in 1868, Donders examined the relationship between respiration, HR, and the vagus nerve. ${ }^{27}$ In 1920, Bainbridge explained RSA in terms of alterations in baroreceptor and volume receptor responses associated with respiratory alterations in thoracic pressure. ${ }^{28}$ Moreover, in 1915, the studies of Eppinger and Hess focused on clinical issues related to putative abnormalities in autonomic functions. They focused on the potential role of the ANS in atypical physiological responses and clinical disorders. Their studies also emphasized the activity of the vagus nerve, which may allow pharmacological manipulations and potential treatments. ${ }^{29}$ In 1967, Wolf viewed $\mathrm{HRV}$ as reflecting brain-vagal-heart communication. ${ }^{30}$ Wolf provided an important connection between clinical re- search and psychophysiology. After that, HRV was treated as a descriptive variable without being attributed to any specific physiological state. At present, understanding of HRV interpretation is increasing, and we are also aware of the interaction between HRV's underlying physiological mechanisms and behavioral processes. ${ }^{29}$

HRV variables are summarized in Tables 1 and $2 .{ }^{15}$ In 1996, the Task Force of the European Society of Cardiology (ESC) and the North American Society of Pacing and Electrophysiology (NASPE) defined and established standards for the measurement, physiological interpretation, and clinical use of HRV. Time-domain and frequency-domain indices and geometric measures are standard clinical parameters. ${ }^{15}$ Time-domain analysis measures variation in HR over time or the intervals between successive normal cardiac cycles. Time-domain analysis of recording data involves simple calculations of mean normal-to-normal $(\mathrm{NN})$ intervals and the variance between $\mathrm{NN}$ intervals. One of the simplest time-domain analysis variables is the standard deviation of the NN interval (SDNN; i.e., the standard deviation of NN). When HRV is large and irregular, the SDNN value increases. Therefore, SDNN is an index of physiological resilience against stress. In contrast to SDNN, which is computed directly from the NN interval, the root mean square of the successive differences (RMSSD), number of interval differences of successive $\mathrm{NN}$ intervals greater than $50 \mathrm{~ms}$ (NN50), and proportion derived by dividing NN50 by the total number of NN intervals (pNN50) are derived from

Table 1. Heart rate variability (HRV) time-domain measures ${ }^{15}$

\begin{tabular}{|c|c|c|}
\hline Variable & Units & Description \\
\hline \multicolumn{3}{|l|}{ Statistical measures } \\
\hline SDNN & $\mathrm{ms}$ & Standard deviation of all NN intervals \\
\hline SDANN & $\mathrm{ms}$ & Standard deviation of the averages of NN intervals in all 5-minute segments of the entire recording \\
\hline RMSSD & $\mathrm{ms}$ & The square root of the mean of the sum of the squares of differences between adjacent NN intervals \\
\hline SDNN index & $\mathrm{ms}$ & Mean of the standard deviations of all NN intervals for all 5-minute segments of the entire recording \\
\hline SDSD & $\mathrm{ms}$ & Standard deviation of differences between adjacent NN intervals \\
\hline NN50 count & & $\begin{array}{l}\text { Number of pairs of adjacent } \mathrm{NN} \text { intervals differing by more than } 50 \mathrm{~ms} \text { in the entire recording; three } \\
\text { variants are possible counting all such NN intervals pairs or only pairs in which the first or the second } \\
\text { interval is longer }\end{array}$ \\
\hline pNN50 & $\%$ & NN50 count divided by the total number of all NN intervals \\
\hline \multicolumn{3}{|l|}{ Geometric measures } \\
\hline $\begin{array}{l}\text { HRV triangular } \\
\text { index }\end{array}$ & & $\begin{array}{l}\text { Total number of all NN intervals divided by the height of the histogram of all } \mathrm{NN} \text { intervals measured on } \\
\text { a discrete scale with bins of } 7.8125 \mathrm{~ms}(1 / 128 \text { seconds) }\end{array}$ \\
\hline TINN & $\mathrm{ms}$ & $\begin{array}{l}\text { Baseline width of the minimum square difference triangular interpolation of the highest peak of the } \\
\text { histogram of all NN intervals }\end{array}$ \\
\hline Differential index & $\mathrm{ms}$ & $\begin{array}{l}\text { Difference between the widths of the histogram of differences between adjacent NN intervals measured } \\
\text { at selected heights (e.g., at the levels of 1,000 and 10,000 samples) }\end{array}$ \\
\hline Logarithmic index & & $\begin{array}{l}\text { Coefficient } \varphi \text { of the negative exponential curve } \mathrm{k} \cdot \mathrm{e}^{-\varphi \mathrm{t}} \text {, which is the best approximation of the histogram } \\
\text { of absolute differences between adjacent } \mathrm{NN} \text { intervals }\end{array}$ \\
\hline
\end{tabular}

NN: normal-to-normal 
Table 2. Heart rate variability (HRV) frequency-domain measures ${ }^{15}$

\begin{tabular}{|c|c|c|c|}
\hline Variable & Units & Description & Frequency range \\
\hline \multicolumn{4}{|c|}{ Analysis of short-term recordings (5 min) } \\
\hline 5-min total power & $\mathrm{ms}^{2}$ & The variance of NN intervals over the temporal segment & $\approx \leq 0.4 \mathrm{~Hz}$ \\
\hline VLF & $\mathrm{ms}^{2}$ & Power in VLF range & $\leq 0.04 \mathrm{~Hz}$ \\
\hline LF & $m s^{2}$ & Power in LF range & $0.04-0.15 \mathrm{~Hz}$ \\
\hline LF norm & nu & $\mathrm{LF}$ power in normalized units $\mathrm{LF} /($ total power-VLF $) \times 100$ & \\
\hline $\mathrm{HF}$ & $\mathrm{ms}^{2}$ & Power in HF range & $0.15-0.4 \mathrm{~Hz}$ \\
\hline HF norm & nu & HF power in normalized units $\mathrm{HF} /($ total power-VLF $) \times 100$ & \\
\hline $\mathrm{LF} / \mathrm{HF}$ & & Ratio LF $\left(\mathrm{ms}^{2}\right) / \mathrm{HF}\left(\mathrm{ms}^{2}\right)$ & \\
\hline \multicolumn{4}{|c|}{ Analysis of entire 24 hours } \\
\hline Total power & & Variance of all NN intervals & $\approx \leq 0.4 \mathrm{~Hz}$ \\
\hline ULF & & Power in the ULF range & $\leq 0.003 \mathrm{~Hz}$ \\
\hline $\mathrm{LF}$ & & Power in the VLF range & $0.003-0.04 \mathrm{~Hz}$ \\
\hline VLE & & Power in the LF range & $0.04-0.15 \mathrm{~Hz}$ \\
\hline $\mathrm{HF}$ & & Power in the HF range & $0.15-0.4 \mathrm{~Hz}$ \\
\hline$\alpha$ & & Slope of the linear interpolation of the spectrum in a log-log scale & $\approx \leq 0.04 \mathrm{~Hz}$ \\
\hline
\end{tabular}

VLF: very low frequency band, LF: low-frequency band, HF: high-frequency band, ULF: ultra low frequency band

the difference between adjacent $\mathrm{NN}$ intervals. These variables are impacted by the PNS, as they reflect beat-to-beat changes. $^{31,32}$ Power Spectral Density (PSD) analysis of the frequency domain provides information about how power is distributed (i.e., the variance) as a function of frequency, which allows autonomic balance to be quantified at any given time. By using PSD analysis to understand HRV, we can distinguish between the activity of the SNS and PNS. Frequency-domain analysis is preferred for short-term measurements (i.e., $5 \mathrm{~min}$ ). PSD analysis allows the intensity of the HRV spectral components [i.e., the high-frequency band (HF), low-frequency band (LF), and very low frequency band (VLF)] to be determined. Different HRV spectral components are associated with either the sympathetic or parasympathetic branches of the ANS. The HF is a measure of PNS activity, as it reflects the activity of the vagus nerve, whereas LF reflects the activity of the SNS. ${ }^{33,34}$

\section{Studies of HRV reactivity to psychological stressors in healthy human participants}

Sloan et al. ${ }^{35}$ analyzed 24-h electrocardiographic recordings from 33 healthy participants to examine the association between the RR interval, HRV responses, and periodic diary entries measuring physical position, negative affect, and time of day. As expected, their results showed that increases in stress were associated with decreases in the RR interval. Moreover, psychological stress was significantly associated with an increase in the LF/HF ratio, suggesting increased SNS activity during stressful periods of the day. ${ }^{35}$ Using a questionnaire survey and short-term HRV recordings of 223 healthy male white-collar workers, Kageyama et al. ${ }^{36}$ investigated the rela- tionship between the number of job stressors, self-reported sleep quality, and daytime autonomic activities. They found no correlation between the HRV parameters and five job stressor scores. ${ }^{36}$ However, subsequent studies have reported that some HRV indicators reflect psychological stress. Studies of healthy human individuals that examined HRV variation associated with psychologically stressful situations are summarized in Table 3. There was heterogeneity among the studies concerning the type of stress-eliciting task used and HRV reactivity (i.e., laboratory environment task or subjective stress reports). Moreover, the HRV reactivity studies were either short-term (5 min) or continuous 24-h studies. In most studies, HRV variables changed in response to stress induced by various methods. However, the presence of significant variation in HRV variables was inconsistent. The most frequently reported factor associated with variation in HRV variables was low parasympathetic activity, which is characterized by a decrease in the HF and an increase in the LF. Dimitriev et al. ${ }^{37}$ recently reported that mental stress leads to an increase in predictability, RR interval regularity, and reduced complexity. This reflects a change toward more stable and periodic HR behavior under stress. Reduced HRV and inhibited parasympathetic activation increase vulnerability to future stress.

\section{Neurobiological evidence of $\mathrm{HRV}$ as a stress measurement}

Many of the studies examined were consistent with Claude Bernarde's (1865) finding that the vagus nerve serves as a structural and functional link between the brain and the heart. His work was among the earliest to systematically investigate 


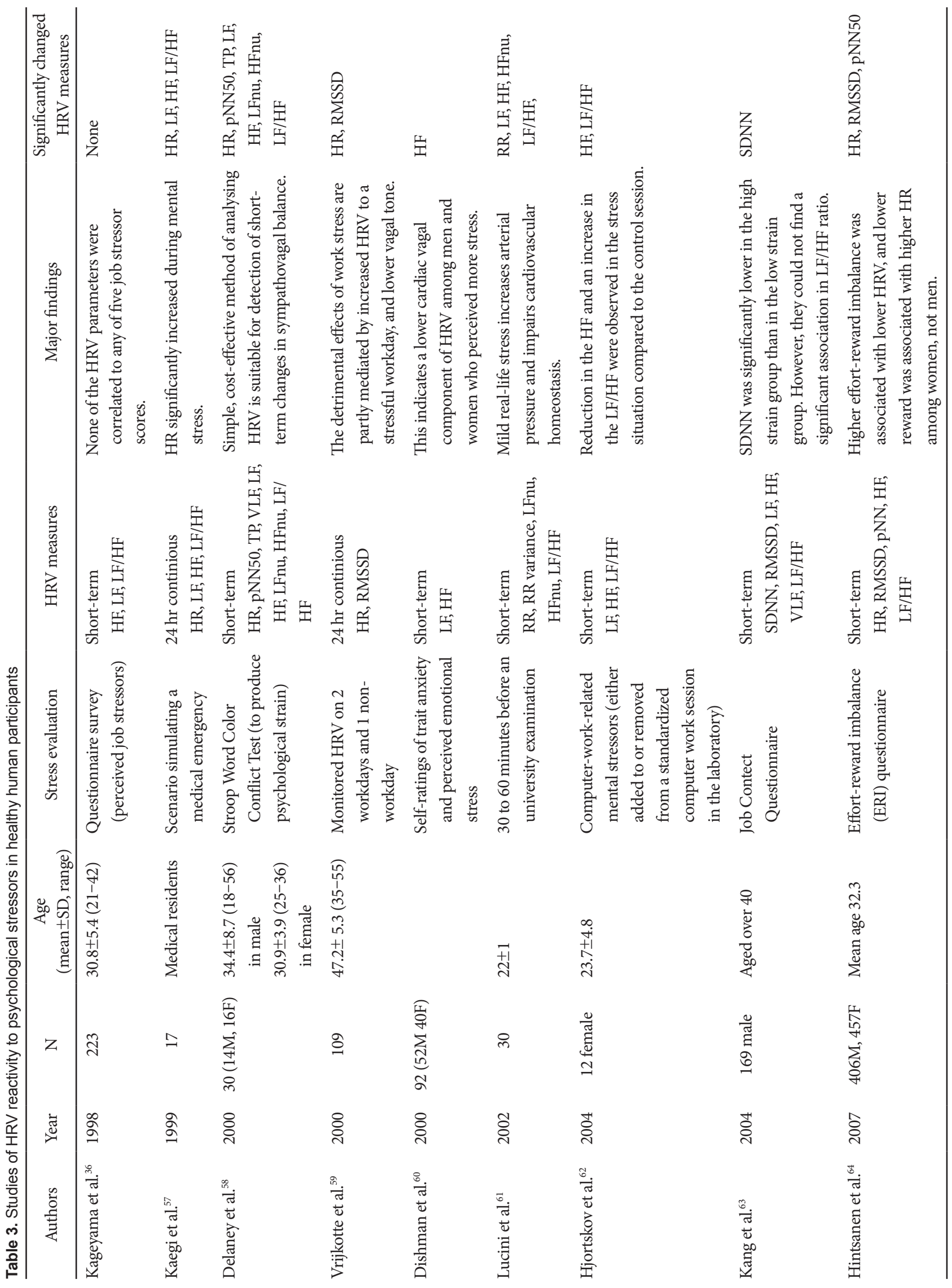


HG Kim et al.

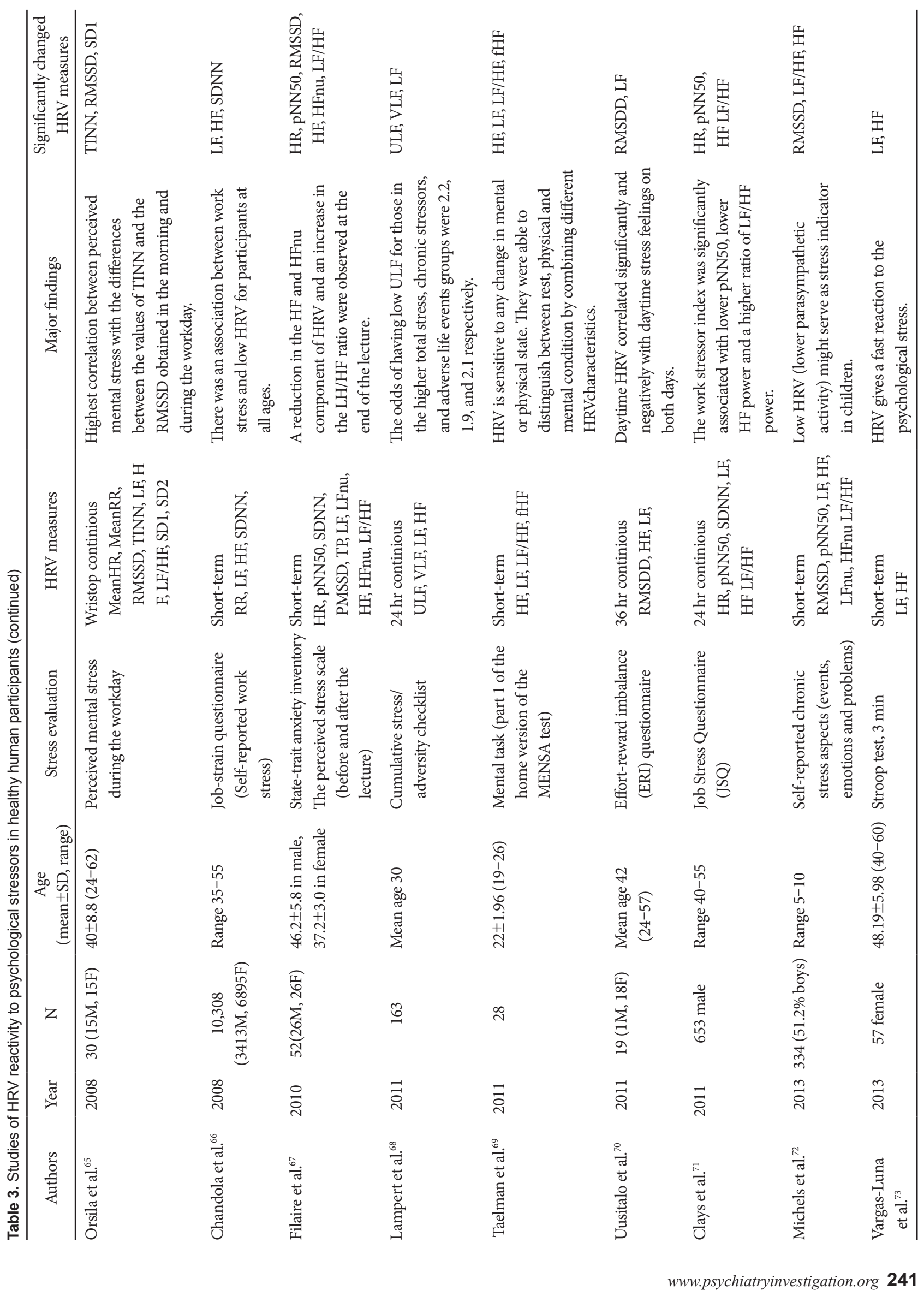




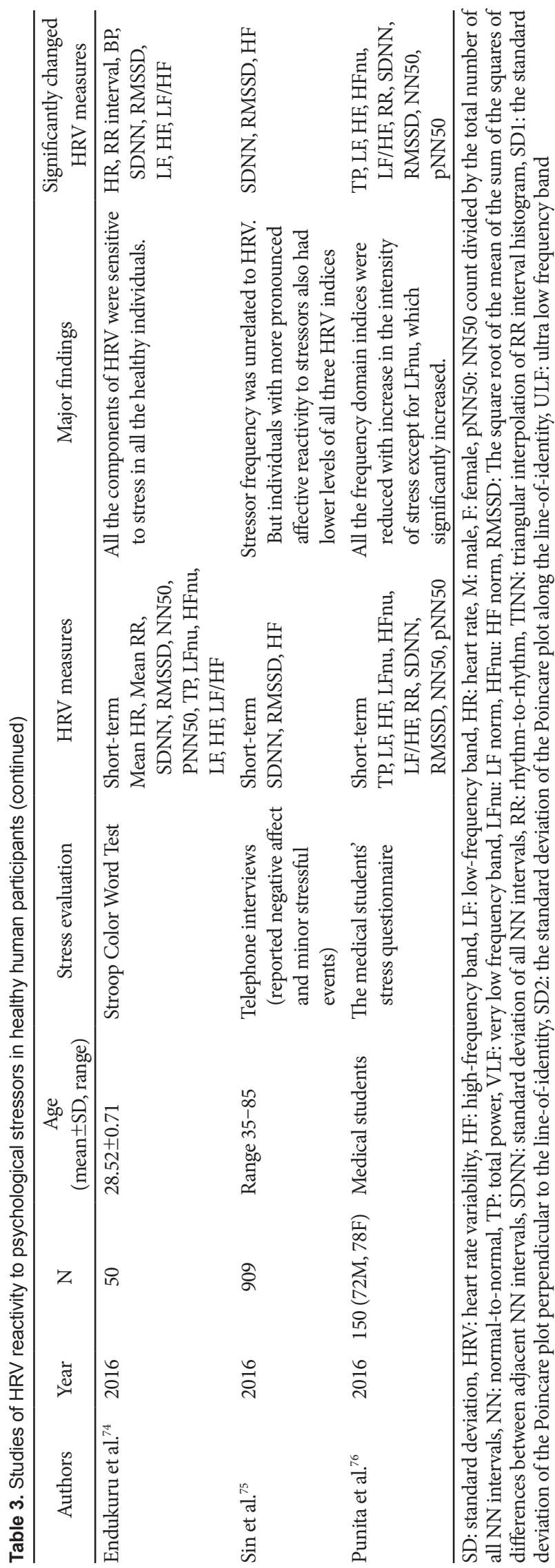

the connections between the brain and the heart. ${ }^{38}$ Perceptions of threat and safety are common core elements of "stressors." Continuous perception of threats is harmful to the human body and affects the regulation of hippocampal circuits, endocrine systems, ANS, and others. ${ }^{39-42}$ If an organism is to avoid a chronic state of threat, it is essential to determine whether threat assessment is appropriate depending on the context. The prefrontal cortex (PFC) and medial PFC (mPFC), in particular, appear to be important in this appraisal process. ${ }^{3,38}$ In safe contexts, threat representations in the amygdala would be inhibited by the ventromedial PFC (vmPFC). A manipulation of the vmPFC, such as pharmacological intervention, can help to inhibit subcortical threat circuits and reduce stress responses. ${ }^{43-46}$ Studies have shown reciprocal inhibition of the PFC and amygdala. ${ }^{47-49}$ The aim of this study was to investigate the relationship between HRV and neurogenic rhythms. These inhibitory prefrontal processes can be assessed using measures of vagal function, such as HRV. A meta-analysis of $\mathrm{HRV}$ neuroimaging studies found a link between HRV and brain regions (e.g., the ventral aspect of the mPFC) associated with reduced threat perception. ${ }^{3} \mathrm{HRV}$ can measure the degree of functional integration of the axes connecting vmPFC, brainstem and peripheral anatomy and can represent the degree to which it provides flexible control over ANS.

\section{Clinical applications of HRV}

In view of observations of stress-associated variation in HRV and existing neurobiological evidence, HRV may be used as an objective assessment of stress and mental health. However, since psychiatric illnesses have numerous causes and symptoms, consistent biological measurements are difficult to acquire in individuals with mental illness. Thus, a patient's psychological and medical history should be equally considered when interpreting HRV results. Therefore, HRV can be considered a tool that reflects heart activity and overall autonomic health, rather than specific mental illnesses or disease states. Since the concept of stress includes biological and psychological factors, objective and physiological evaluations as well as self-reporting should be integrated when evaluating stress, using HRV in clinical practice. Many studies have found an association between mental health and HRV. However, since HRV is associated with various stress factors, stress duration, individual coping ability, and lifestyle habits, these studies are difficult to interpret. Many physical conditions and lifestyle habits can affect HRV results, including physiological factors (e.g., breathing, circadian rhythms, and posture), non-modifiable factors (e.g., age, sex, and genetic factors), modifiable lifestyle factors (e.g., obesity, metabolic syndrome, physical activity, smoking, and drinking), and other factors [e.g., medication (e.g., anticholinergics, stimulants, and beta- 
blockers) $].^{50-55}$

Hans Seyle ${ }^{1,56}$ proposed a three-stage stress response model. The first stage is the "alarm reaction stage," in which the body reacts to a stressor with the fight-or-flight response and activates the SNS. The second stage is the "resistance stage," in which the body adapts to the stressor. During this stage, the PNS restores many physiological functions to normal, while the body focuses its resources against the stressor. Although the outward appearance of the organism seems normal, blood glucose, cortisol, and adrenalin levels remain elevated. If a stressor continues beyond the body's capacity to cope, the organism exhausts its resources, making it susceptible to disease or death. This "exhaustion stage" is reached when the acquired adaptation or resistance is lost. When assessing the severity of a patient's stress level in a clinical setting, HRV results should be interpreted with this three-stage process in mind. At each stage, stress causes changes in physiological function, which are reflected in HRV changes. Due to the variety of potential stressors and individual stress responses, it is essential to understand the overall autonomic context and examine a patient's medical and psychological history when interpreting the relationship between HRV and stress.

\section{DISCUSSION}

HRV is sensitive to changes in ANS activity (i.e., changes in the SNS and PNS) associated with stress. In most studies, HRV variables changed in response to stress induced by various methods. The most frequently reported factor associated with variation in HRV variables was low parasympathetic activity, which is characterized by a decrease in the HF and an increase in the LF. HRV may be associated with the activity of a flexible network of neural structures, which are dynamically organized in response to environmental challenges. Indeed, neuroimaging studies suggest that HRV may be linked to reduced threat perception, mediated by cortical regions (e.g., the ventral aspect of the mPFC) involved in the appraisal of stressful situations. In clinical situations, HRV can be considered a tool that reflects heart activity and overall autonomic health, rather than specific mental illnesses or disease states. Thus, when evaluating the relationship between stress and HRV, it is essential to consider the overall autonomic context as well as the patient's medical and psychological history.

\section{Acknowledgements}

This work was supported by the National Research Foundation of Korea (NRF) grant funded by the Korean government (MSIP: Ministry of Science, ICT, and Future Planning) (No. 216C000671).

\section{REFERENCES}

1. Selye H. The Stress of Life. New York: McGraw-Hill; 1956.
2. Campkin M. Stress management in primary care. Fam Pract 2000;17: 98-99.

3. Thayer JF, Ahs F, Fredrikson M, Sollers JJ, Wager TD. A meta-analysis of heart rate variability and neuroimaging studies: implications for heart rate variability as a marker of stress and health. Neurosci Biobehav Rev 2012;36:747-756.

4. Malik M, Camm AJ. Heart Rate Variability. Armonk, NY: Futura Pub. Co.; 1995.

5. Rajendra Acharya U, Paul Joseph K, Kannathal N, Lim CM, Suri JS. Heart rate variability: a review. Med Biol Eng Comput 2006;44:10311051.

6. Sztajzel J. Heart rate variability: a noninvasive electrocardiographic method to measure the autonomic nervous system. Swiss Med Wkly 2004;134:514-522.

7. Marques AH, Silverman MN, Sternberg EM. Evaluation of stress systems by applying noninvasive methodologies: measurements of neuroimmune biomarkers in the sweat, heart rate variability and salivary cortisol. Neuroimmunomodulation 2010;17:205-208.

8. Rotenberg S, McGrath JJ. Inter-relation between autonomic and HPA axis activity in children and adolescents. Biol Psychol 2016;117:16-25.

9. Porges SW. Cardiac vagal tone: a physiological index of stress. Neurosci Biobehav Rev 1995;19:225-233.

10. Curtis AL, Lechner SM, Pavcovich LA, Valentino RJ. Activation of the locus coeruleus noradrenergic system by intracoerulear microinfusion of corticotropin-releasing factor: effects on discharge rate, cortical norepinephrine levels and cortical electroencephalographic activity. J Pharmacol Exp Ther 1997;281:163-172.

11. Egliston KA, McMahon C, Austin MP. Stress in pregnancy and infant HPA axis function: conceptual and methodological issues relating to the use of salivary cortisol as an outcome measure. Psychoneuroendocrinology 2007;32:1-13.

12. Berntson GG, Cacioppo JT. Heart Rate Variability: Stress and Psychiatric Conditions. In: Malik M, Camm J, Editors. Dynamic Electrocardiography: Blackwell Publishing, 2007, p.57-64.

13. Berntson GG, Cacioppo JT, Binkley PF, Uchino BN, Quigley KS, Fieldstone A. Autonomic cardiac control. III. Psychological stress and cardiac response in autonomic space as revealed by pharmacological blockades. Psychophysiology 1994;31:599-608.

14. Ditto B, France C. Carotid baroreflex sensitivity at rest and during psychological stress in offspring of hypertensives and non-twin sibling pairs. Psychosom Med 1990;52:610-620.

15. Heart rate variability: standards of measurement, physiological interpretation and clinical use. Task Force of the European Society of Cardiology and the North American Society of Pacing and Electrophysiology. Circulation 1996;93:1043-1065.

16. Osterrieder W, Noma A, Trautwein W. On the kinetics of the potassium channel activated by acetylcholine in the S-A node of the rabbit heart. Pflügers Archiv 1980;386:101-109.

17. Noma A, Trautwein W. Relaxation of the ACh-induced potassium current in the rabbit sinoatrial node cell. Pflugers Arch 1978;377:193-200.

18. Brown HF, DiFrancesco D, Noble SJ. How does adrenaline accelerate the heart? Nature 1979;280:235-236.

19. Akselrod S, Gordon D, Madwed JB, Snidman NC, Shannon DC, Cohen RJ. Hemodynamic regulation: investigation by spectral analysis. Am J Physiol 1985;249:H867-H875.

20. Levy MN. Sympathetic-parasympathetic interactions in the heart. Circ Res 1971;29:437-445.

21. Kjellgren O, Gomes JA. Heart rate variability and baroreflex sensitivity in myocardial infarction. Am Heart J 1993;125:204-215.

22. Caruana-Montaldo B, Gleeson K, Zwillich CW. The control of breathing in clinical practice. Chest 2000;117:205-225.

23. Tian K, Qin J, Huang L, Long M, Wu J, Yu S, et al. [The effect of aerobic and anaerobic endurance training on the regulating function of autonomic nervous system and its significance]. Sheng Wu Yi Xue Gong Cheng Xue Za Zhi 2006;23:1020-1023. 
24. Aubert AE, Seps B, Beckers F. Heart rate variability in athletes. Sports Med 2003;33:889-919.

25. Vanderlei LC, Pastre CM, Hoshi RA, Carvalho TD, Godoy MF. Basic notions of heart rate variability and its clinical applicability. Rev Bras Cir Cardiovasc 2009;24:205-217.

26. Ludwig C. Beitrage zur Kenntniss des Einflusses der Respriations bewegungen auf den Blutlauf im Aortensysteme. Arch Anat Physiol 1847;13: 242-3027.

27. Donder FC. Zur Physiologies des Nervus vagus. Pfluegers Arch Ges Physiol 1868;1:331-361.

28. Bainbridge FA. The relation between respiration and the pulse-rate. J Physiol 1920;54:192-202.

29. Berntson GG, Bigger JT Jr, Eckberg DL, Grossman P, Kaufmann PG, Malik M, et al. Heart rate variability: origins, methods, and interpretive caveats. Psychophysiology 1997;34:623-648.

30. Wolf $S$. The end of the rope: the role of the brain in cardiac death. Can Med Assoc J 1967;97:1022-1025.

31. Kleiger RE, Stein PK, Bosner MS, Rottman JN. Time domain measurements of heart rate variability. Cardiol Clin 1992;10:487-498.

32. Hnatkova K, Copie X, Staunton A, Malik M. Numeric processing of Lorenz plots of R-R intervals from long-term ECGs. Comparison with time-domain measures of heart rate variability for risk stratification after myocardial infarction. J Electrocardiol 1995;28(Suppl):74-80.

33. Ori Z, Monir G, Weiss J, Sayhouni X, Singer DH. Heart rate variability. Frequency domain analysis. Cardiol Clin 1992;10:499-537.

34. Malliani A, Pagani M, Lombardi F, Cerutti S. Cardiovascular neural regulation explored in the frequency domain. Circulation 1991;84:482492.

35. Sloan RP, Shapiro PA, Bagiella E, Boni SM, Paik M, Bigger JT Jr, et al. Effect of mental stress throughout the day on cardiac autonomic control. Biol Psychol 1994;37:89-99.

36. Kageyama T, Nishikido N, Kobayashi T, Kurokawa Y, Kaneko T, Kabuto M. Self-reported sleep quality, job stress, and daytime autonomic activities assessed in terms of short-term heart rate variability among male white-collar workers. Ind Health 1998;36:263-272.

37. Dimitriev DA, Saperova EV. [Heart rate variability and blood pressure during mental stress]. Ross Fiziol Zh Im I M Sechenova 2015;101:98-107.

38. Thayer JF, Lane RD. Claude Bernard and the heart-brain connection: further elaboration of a model of neurovisceral integration. Neurosci Biobehav Rev 2009;33:81-88.

39. Seeman TE, McEwen BS, Rowe JW, Singer BH. Allostatic load as a marker of cumulative biological risk: MacArthur studies of successful aging. Proc Natl Acad Sci U S A 2001;98:4770-4775.

40. Sapolsky RM. Why stress is bad for your brain. Science 1996;273:749750 .

41. McEwen BS. From molecules to mind. Stress, individual differences, and the social environment. Ann N Y Acad Sci 2001;935:42-49.

42. Chrousos GP, Kino T. Interactive functional specificity of the stress and immune responses: the ying, the yang, and the defense against 2 major classes of bacteria. J Infect Dis 2005;192:551-555.

43. Quirk GJ, Beer JS. Prefrontal involvement in the regulation of emotion: convergence of rat and human studies. Curr Opin Neurobiol 2006;16: 723-727.

44. Milad M, Vidal-Gonzalez I, Quirk G. Electrical stimulation of medial prefrontal cortex reduces conditioned fear in a temporally specific manner. Behav Neurosci 2004;118:389-394.

45. Milad MR, Quirk GJ. Neurons in medial prefrontal cortex signal memory for fear extinction. Nature 2002;420:70-74.

46. Amat J, Paul E, Watkins LR, Maier SF. Activation of the ventral medial prefrontal cortex during an uncontrollable stressor reproduces both the immediate and long-term protective effects of behavioral control. Neuroscience 2008;154:1178-1186.

47. Schiller D, Levy I, Niv Y, LeDoux JE, Phelps EA. From fear to safety and back: reversal of fear in the human brain. J Neurosci 2008;28:1151711525.
48. Milad MR, Wright CI, Orr SP, Pitman RK, Quirk GJ, Rauch SL. Recall of fear extinction in humans activates the ventromedial prefrontal cortex and hippocampus in concert. Biol Psychiatry 2007;62:446-454.

49. Delgado MR, Nearing KI, LeDoux JE, Phelps EA. Neural circuitry underlying the regulation of conditioned fear and its relation to extinction. Neuron 2008;59:829-838.

50. Romanowicz M, Schmidt JE, Bostwick JM, Mrazek DA, Karpyak VM. Changes in heart rate variability associated with acute alcohol consumption: current knowledge and implications for practice and research. Alcohol Clin Exp Res 2011;35:1092-1105.

51. Spaak J, Tomlinson G, McGowan CL, Soleas GJ, Morris BL, Picton P, et al. Dose-related effects of red wine and alcohol on heart rate variability. Am J Physiol Heart Circ Physiol 2010;298:H2226-H2231.

52. Dinas PC, Koutedakis Y, Flouris AD. Effects of active and passive tobacco cigarette smoking on heart rate variability. Int J Cardiol 2013;163: 109-115.

53. Felber Dietrich D, Ackermann-Liebrich U, Schindler C, Barthelemy JC, Brandli O, Gold DR, et al. Effect of physical activity on heart rate variability in normal weight, overweight and obese subjects: results from the SAPALDIA study. Eur J Appl Physiol 2008;104:557-565.

54. Min KB, Min JY, Paek D, Cho SI. The impact of the components of metabolic syndrome on heart rate variability: using the NCEP-ATP III and IDF definitions. Pacing Clin Electrophysiol 2008;31:584-591.

55. Altuncu ME, Baspinar O, Keskin M. The use of short-term analysis of heart rate variability to assess autonomic function in obese children and its relationship with metabolic syndrome. Cardiol J 2012;19:501-506.

56. Selye H. Stress in Health and Disease. Boston: Butterworths; 1976.

57. Kaegi DM, Halamek LP, Van Hare GF, Howard SK, Dubin AM. Effect of mental stress on heart rate variability: validation of simulated operating and delivery room training modules. Pediatr Res 1999;45:77A.

58. Delaney JP, Brodie DA. Effects of short-term psychological stress on the time and frequency domains of heart-rate variability. Percept Mot Skills 2000;91:515-524.

59. Vrijkotte TG, van Doornen LJ, de Geus EJ. Effects of work stress on ambulatory blood pressure, heart rate, and heart rate variability. Hypertension 2000;35:880-886.

60. Dishman RK, Nakamura Y, Garcia ME, Thompson RW, Dunn AL, Blair SN. Heart rate variability, trait anxiety, and perceived stress among physically fit men and women. Int J Psychophysiol 2000;37:121-133.

61. Lucini D, Norbiato G, Clerici M, Pagani M. Hemodynamic and autonomic adjustments to real life stress conditions in humans. Hypertension 2002;39:184-188.

62. Hjortskov N, Rissén D, Blangsted AK, Fallentin N, Lundberg U, Søgaard $\mathrm{K}$. The effect of mental stress on heart rate variability and blood pressure during computer work. Eur J Appl Physiol 2004;92:84-89.

63. Kang MG, Koh SB, Cha BS, Park JK, Woo JM, Chang SJ. Association between job stress on heart rate variability and metabolic syndrome in shipyard male workers. Yonsei Med J 2004;45:838-846.

64. Hintsanen M, Elovainio M, Puttonen S, Kivimaki M, Koskinen T, Raitakari OT, et al. Effort-reward imbalance, heart rate, and heart rate variability: the cardiovascular risk in young finns study. Int J Behav Med 2007;14:202-212.

65. Orsila R, Virtanen M, Luukkaala T, Tarvainen M, Karjalainen P, Viik J, et al. Perceived mental stress and reactions in heart rate variability- a pilot study among employees of an electronics company. Int J Occup Saf Ergon 2008;14:275-283.

66. Chandola T, Britton A, Brunner E, Hemingway H, Malik M, Kumari $\mathrm{M}$, et al. Work stress and coronary heart disease: what are the mechanisms? Eur Heart J 2008;29:640-648.

67. Filaire E, Portier H, Massart A, Ramat L, Teixeira A. Effect of lecturing to 200 students on heart rate variability and alpha-amylase activity. Eur J Appl Physiol 2010;108:1035-1043.

68. Lampert R, Tuit K, Sinha R. Chronic stress and adverse life events are associated with depressed autonomic function as measured by heart rate variability. Circulation 2011;124:A10441. 
69. Taelman J, Vandeput S, Gligorijevic I, Spaepen A, Van Huffel S. Timefrequency heart rate variability characteristics of young adults during physical, mental and combined stress in laboratory environment. Conf Proc IEEE Eng Med Biol Soc 2011;2011:1973-1976.

70. Uusitalo A, Mets T, Martinmaki K, Mauno S, Kinnunen U, Rusko H. Heart rate variability related to effort at work. Appl Ergon 2011;42:830838.

71. Clays E, De Bacquer D, Crasset V, Kittel F, de Smet P, Kornitzer M, et al. The perception of work stressors is related to reduced parasympathetic activity. Int Arch Occup Environ Health 2011;84:185-191.

72. Michels N, Sioen I, Clays E, De Buyzere M, Ahrens W, Huybrechts I, et al. Children's heart rate variability as stress indicator: association with reported stress and cortisol. Biol Psychol 2013;94:433-440.

73. Vargas-Luna M, Huerta-Franco MR, Montes JB. Evaluation of the Car- diac Response to Psychological Stress by Short-Term ECG Recordings: Heart Rate Variability and Detrended Fluctuation Analysis. In: Long M, editor. World Congress on Medical Physics and Biomedical Engineering May 26-31, 2012, Beijing, China. Berlin, Heidelberg: Springer Berlin Heidelberg; 2013, p.333-335.

74. Endukuru CK, Tripathi S. Evaluation of cardiac responses to stress in healthy individuals- a non invasive evaluation by heart rate variability and stroop test. Int J Sci Res 2016;5:286-289.

75. Sin NL, Sloan RP, McKinley PS, Almeida DM. Linking daily stress processes and laboratory-based heart rate variability in a national sample of midlife and older adults. Psychosom Med 2016;78:573-582.

76. Punita P, Saranya K, Kumar SS. Gender difference in heart rate variability in medical students and association with the level of stress. Natl J Physiol Pharm Pharmacol 2016;6:431-437. 